\title{
El legado africano en Cuba
}

\author{
N atalia Bolívar
}

Fecha de recepción: 1995

\section{Resumen}

En este artículo se trata de la actividad religiosa, o parareligiosa, practicada en amplios sectores de la población de color de Cuba, que hunde sus raíces en su anterior vida en África y en la esclavitud. Porque los esclavos negros mantuvieron inicialmente el culto de sus antiguos dioses, y también de sus costumbres y asociaciones, que en al guna forma sobrevivieron y a la larga dieron lugar a varios sistemas religiosos en los que restructuraron sus creencias. Y así las prácticas religiosas de la cultura yoruba cristalizaron en un solo cuerpo litúrgico al que denominaron la Regla de 0 cha o santería; las procedentes del C ongo y Angola en la Regla de Palo o mayombe, y en forma parecida nacieron los preceptos religiosos de la sociedad secreta Abakuá, procedente de N igeria; las casas de babalawos, etc. Con la independencia (1898) paradójicamente se produjo cierta persecución de corte racista contra la población de color, hasta que en 1940 se promulgó una nueva Constitución favorable a la libertad religiosa. Por último el artículo describe someramente las distintas actitudes que se han tenido desde 1959 y se cierra con un cuadro que describe el sincretismo religioso existente entre las distintas vírgenes cristianas y divinidades afrocubanas equivalentes.

Palabras clave: santería o Regla de 0 cha, esclavitud, cabildos, Partido de los Independientes de Color, santeros y paleros (sacerdotes), casas de babalawos (templos), religión, creencias.

Abstract. African roots of Cuba

The article deals with religious activity and para-religious practices among coloured Cuban population, due to African roots and slavery. Yoruba cultural and religious traditions have developed into a unique liturgy called the Regla de 0 cha or Santería, those coming from Congo and Angola have influenced the Regla del Palo o M ayombe, etc. Since 1940 Religious freedom has been garanteed. Since 1959 different attitudes have developed into the actual religious sincretism

Key words: Santería, religion, slavery, Coloured Independent Party.

\section{Sumario}

0 tras voces se entremezclan

Principales manifestaciones religiosas africanas en Cuba
La República de Cuba de 1900 a 1959

Contrapartida Revolución

Cubana - religiones afrocubanas

Precursores de la Regla de 0 cha o santería 
Traemos el humo en la mañana,

y el fuego sobre la noche,

y el cuchillo, como un duro pedazo en la luna,

acto para las pieles bárbaras;

traemos los caimanes en el fango

y el arco que dispara nuestras ansias,

y el cinturón del trópico,

y el espíritu limpio.

Traemos

nuestro rasgo al perfil definitivo de América.

Nicolás Guillén. Llegada (poema)

En el vientre gestor de los navíos negreros se transportaron no sólo hombres, mujeres y niños, sino también deidades ${ }^{1}$, creencias y concepciones. El pensamiento mágico-religioso de las distintas etnias africanas tuvo en nuestras tierras americanas segunda patria. M úsica, danzas, religión, ética, costumbres de ancestrales culturas arrancadas a la fuerza y trasplantadas no sólo a latitudes propicias, sino también a mentes receptivas en las cuales fantasía y maravilla habían sentado carta de ciudadanía. Y desde luego, los cuerpos primero semejantemente receptivos. La mezcla, la simbiosis, la fusión de elementos conformó, aglutinó y preservó un legado sensible hasta muy actuales días y que une nuestra isla caribeña con un cordón umbilical a la América mestiza con el eco de cientos de años de tambores rituales que repican en su sangre. Tierras de mulatería las nuestras, de finas orejas para el relato de orígenes y patakies ${ }^{2}$, y de rápidos gestos «por si acaso... », en que yerbas, animales y hombres muestran el perfil definitivo y definitorio de nacionalidades que se identifican por sus rasgos caracterizadores.

En los anales que se guardan en el Archivo $\mathrm{N}$ acional se hace mención a la existencia desde 1568 de facto, aunque no de jure, de cabildos negros en Cuba, llamados «C abildos de N ación», especie de organizaciones de negros esclavos agrupados por sus etnias de origen. Estos cabildos tienen una repercusión transcendental en las instituciones sociales y religiosas de los negros. Las actividades principales de estas organizaciones se enmarcaban en la organización de sus bailes, músicas e instrumentos tradicionales, que constituían la actividad principal, pero además adquirieron también un carácter de asociaciones de auxilio y ben eficencia social entre sus integrantes que, en ocasiones, llegaban incluso a comprar la libertad de al guna negra esclava. Aunque los cabildos estaban siempre bajo la protección de una virgen de la I glesia católica, en realidad fueron un factor principal, durante los muchos años en que se autorizó legalmente

1. Divinidad de la mitología.

2. N arración de leyendas y fábulas concernientes a los orishas y sus caminos o avatares, con una moraleja que ayuda a la definición de sus dones o atributos. 
su existencia, que contribuyó a mantener y desarrollar una religión propia de los negros. A su vez, la I glesia católica, durante el período de auge de la plantación esclavista en el siglo xıx, descuidó en exceso su labor de evangelización y catequesis entre los negros esclavos, quienes laboraban en las plantaciones de café y de caña de azúcar lejos de las villas y ciudades.

Los cabildos sólo podían estar integrados por negros nacidos en África, estaba prohibido su ingreso a los hijos de éstos nacidos en Cuba, lo que contribuía también a mantener la tradición religiosa africana.

0 tra corriente importante va a estar constituida por los negros libertos y mestizos que vivían en los barrios extramuros de la ciudad de La H abana. Este sector social desarrollaría hábitos de vida y manifestaciones culturales distintas, no sólo de las de la oligarquía esclavista blanca sino también de las de los negros africanos de los cabildos y de las plantaciones. En este sector se originaría la creación de los «Abakuá», una de las tres corrientes religiosas afrocubanas, la cual enfatizaba, a la par que los aspectos religiosos, su carácter de institución secreta y su inclinación de apoyo, lealtad y cooperación entre sus miembros.

La concepción colonial ista sobre los cabildos los consideraba «una reunión de negros y negras en casas destinadas al efecto los días festivos para tocar sus atabales y tambores». Los cabildos, presididos por un rey escogido entre sus integrantes de más edad, jerarquía tribal o religiosa, o por tres capatanes o capitanes y tres madrinas o matronas, elegidos todos por votación y ubicados por orden jerárquico, eran, en realidad, asociaciones de socorro mutuo, escuelas de la lengua y guardianes de las tradiciones de cada grupo africano $y$, muy espe cialmente, del culto a ciertas deidades como, por ejemplo, el Cabildo de C hangó 3 en el barrio habanero de Pogolotti ${ }^{4}$.

Entre el siglo XVI y fines del siglo XVIII, se van formando los asentamientos en los puntos que serían mas tarde eje del desarrollo socioeconómico de nuestra Isla caribeña. Los esclavos traídos desde un inicio de la costa occidental de África, pasan a formar parte del movimiento poblacional. En parte, muchas de estas etnias habían logrado su libertad, o bien trabajaban para los amos en una armonía aparentemente conciliadora de culturas disímiles.

En la obra monumental de Levi M arrero, Cuba Sociedad y E conomía, aparece en un legajo del Archivo de Indias el reflejo de una queja de una ciudadana contra un rey congo, en Santiago de Cuba, que toca sus «atabales», causándole molestia por el ruido. Esto sucede en tan temprana fecha de 1535. Por medio de un paciente estudio hemos observado que este fenómeno es constante en la isla, apareciendo negros libres o bien trabajando para sus amos en diferentes tareas, muchas de ellas artesanales.

En 1755, el obispo M orell de Santa C ruz oficializa los cabildos, éstos son desde sus inicios las escuelas de la lengua, costumbres, hábitos alimenticios y

3. O risha del fuego, del rayo, del trueno, de la guerra, de los tambores batá, del baile, de la música y de la belleza viril.

4. Barrio de la Ciudad de La H abana. 
creencias religiosas de cada etnia, y forman una unión indisoluble. Entre los cabildos más conocidos están: los de los lucumies, los congos-angolas, los mandingas, los araras y los carabalies, los cuales se conservaron en las tierras de extramuros en $\mathrm{La} H$ abana y en pueblos como San José de las $\mathrm{L}$ ajas y $\mathrm{G}$ uines, y en la provincia de $M$ atanzas, en el puerto de Cárdenas, por sólo nombrar algunos; se cobijaron bajo la advocación de la Virgen M aría ${ }^{5}$, aceptando de una manera respetuosa las condiciones impuestas por la religión oficial de la clase dominante, como diría el obispo M orell de Santa Cruz en su informe a las autoridades españolas y a la C orona: «Y para que estas funciones se practicasen con más satisfacción le previne, por fin, cuidara que sus congregantes se aplicasen a aprender las lenguas de las naciones de los mismos negros. Este fue el primer paso que di para el alivio de estos infelices [... ] después fui informado que en los días festivos se congregaban en 21 casas [... ] con títulos de cabildos, a tocar unos instrumentos llamados tumbas».

Los cabildos, desde su inicio, dejaron su impronta para futuras generaciones. En primera etapa podemos afirmar que las creencias religiosas de más de 200 etnias introducidas en Cuba conservarían su fidelidad en la liturgia a la usanza de su país de origen, conservando la lengua, los toques y las danzas con las características propias y sin influencia del mundo ajeno que las rodeaba.

\section{0 tras voces se entremezclan}

Entre los colonizadores españoles, los ocupantes ingleses y los emigrantes franceses hubo diferencias destinadas a tener consecuencias a largo alcance. L os terceros, unos 30.000 francohaitianos, escapados precipitadamente de la oleada revolucionaria que agitaba la vecina isla, en poco tiempo poblaron parte de la región oriental de $\mathrm{Cuba}$ con ingenios, al godonales y cafetales. Allí mezclaron lengua y prácticas sociales y religiosas dentro de ámbito local para inaugurar una zona de intercambio cultural francohaitiano todavía por estudiar. Los segundos, de comparativamente efímera estancia, si bien marcaron el ámbito económico durante el año que duró su dominación, se limitaron - en lo religioso- a dejarnos algunos elementos del protestantismo que no se fortalecerían - también relativamente — sino en la etapa de la república neocolonial. Los primeros, sin embargo, cuya implantación constituyó, junto con la africana, la otra fuente mayor entre los componentes de la nacionalidad cubana, no afrontaron tanto la evangelización de sus esclavos como las prácticas religiosas de éstos de manera consecuente con sus intereses económicos, políticos y sociales.

La preocupación entre los terratenientes esclavistas por mantener la idiosincrasia de las distintas tribus estaba dirigida a preservar las diferencias, las oposiciones y hasta las rivalidades con el objetivo de obstaculizar su posible unidad en la lucha contra los dueños. El poco y casi nulo adoctrinamiento religioso a

5. Ver cuadro comparativo al final del artículo. 
que eran sometidos los esclavos se correspondía, por otra parte, con la necesidad de los amos de darles una lingua franca, el español, y una religión, la católica, que vinculara a los esclavos no entre sí sino a sus poseedores. $Y$ aunque para finales del siglo XVIII los hacendados azucareros habían abandonado en sus dotaciones la práctica religiosa cotidiana, que robaba no pocas horas semanales a la producción, se mantenían aquellas ceremonias que servían de mínimo disfraz moral a los amos y que también podían ser un freno a la rebeldía negra.

Ese relajamiento ofreció un inapreciable espacio a los esclavos que aprovecharon lo permisivo de la actitud de sus amos, ignorantes de que sus fiestas, su música y sus diversiones eran las formas tradicionales de convocar a las deidades ancestrales y que, en realidad, lo que celebraban era una elaborada liturgia religiosa. (D e haberlo sabido quizás no habrían sido tan complacientes.)

Se resistieron así a la opresión del blanco empeñado en arrancarlos de sus culturas nativas para imponerles la suya. Sobre todo en las poblaciones - más que en los campos- donde de noche podían volver a encontrarse y tomar sus comunidades primitivas; sus rebeldías fueron sin duda el testimonio de una voluntad de escapar, primeramente, de la explotación económica de la que eran objeto por un régimen de trabajo odioso, y de su lucha contra la dominación de una cultura que les era extraña. No es, pues, asombroso, que encontremos en nuestra América civilizaciones africanas 0, al menos, trozos enteros de esas civilizaciones.

M ulata era Cecilia Váldez y no por obra y gracia del Espíritu Santo o de C irilo Villaverde. Las murallas destinadas a proteger la ciudad de ataques de piratas y corsarios y que separaban la población - blancos adentro, negros afuera- no pudieron impedir que La H abana, ya en el pasado siglo, fuera mulata, en lujuriosas génesis de letras: literaria y religiosa.

Pudiéramos resumir que en el período transcurrido entre el siglo XVIII y el $X I X$, la sociedad cubana sufre un cambio en la ética, justificando y creando todos los instrumentos jurídicos, sociales y económicos que permitían mantener al negro sometido a un sistema de esclavitud contra natura, en los barracones y en los campos de caña, Ilevándolo a un aislamiento social y cultural e imponiéndole un solo idioma: el idioma español del amo. En las ciudades el régimen esclavista tenía connotaciones más benignas, matizadas por las relaciones amo-esclavos. Los cabildos se mantenían bajo la observación y el resquemor de las autoridades y de la sociedad, ya que en toda la isla se sucedían levantamientos de esclavos y libertos en búsqueda de la libertad, como por ejemplo la famosa conspiración de la Escalera6.

6. N ota del editor: En 1844 estallaron varias conspiraciones y revueltas de la población negra, en gran parte esclava, y la sociedad blanca criolla las interpretó como un gran complot, al que llamó «la conspiración de la Escalera». Parece ser que los encarcelados, deportados y fusilados fueron miles y el año 1844 es conocido en la historia cubana como el «año del cuero» (del látigo de cuero). 


\section{Principales manifestaciones religiosas africanas en Cuba}

Sabemos, por ejemplo, que hacia los años 1880 vivían numerosos yorubas precursores de lo que sería la Regla de 0 cha o santería en una finca situada en $M$ arianao y llamada «El Palenque». Todos eran ahijados de dos santeros jimaguas ${ }^{7}$ muy populares y celebraban todos los años las festividades de 0 ggún ${ }^{8}$, 0 chaoko y los I beyis ${ }^{10}$, ori shas dueños y patrones, respectivamente, del hierro y los metales, las labranzas y los niños. La santería - nombre popular con que ha bautizado nuestro pueblo a lo que verdaderamente se llama Regla de 0 cha(O chá-orisha: «santo», «deidad») desde su aparición en C uba, con los primeros esclavos unidos en el temor implantado por deidades católicas que infundían el pánico a sus mentes ingenuas, fue un culto individual, familiar, de hondas raíces étnicas. Vivió el esclavo asombrado ante el cambio de su estadio apacible en su África querida por un régimen explotador que no podía entender, por el cruce de un océano lleno de peligros, encadenado, despojado de los hábitos de su vida diaria. Algunos de ellos, de estirpe real y procedentes de tribus con sensibilidades artísticas y estéticas, trasladaron esos conocimientos a descendientes y contemporáneos, que sirven hoy, a nuevas generaciones de cubanos, de inspiración inagotable.

Vamos a dividir el tema en tres períodos que marcan la evolución, la identificación y la interrelación por los que pasaron todas las manifestaciones religiosas hoy llamadas afrocubanas antes y después de 1959 y para nosotros: cubanas.

En las postrimerías de la primera mitad del siglo XVIII, los esclavos practicaban el culto a determinada deidad que imperaba en el seno de la tribu de la que procedían. Por ejemplo: los de 0 yó a Changó, los de Egba ${ }^{11}$ a Yemayá12, los de Ekiti y 0 ndo a 0 ggún, los de I yesá e ljebu a 0 chún ${ }^{13}$. Cada una de esas deidades tenía elementos propios que las hacían diferentes de las demás y, sin embargo, poseían dos denominadores comunes: la piedra y el caracol. Además, coincidían en las nuevas tierras a donde habían llegado en los cantos - lamentaciones por su tierra perdida - y en los toques o llamados secretos a sus adorados orishas.

Al principio del siglo xIX, el alza del contrabando negrero apareja una evolución activa y una reafirmación en las creencias religiosas, tanto de los que ya

7. «M ellizos».

8. D ios de los minerales, de las montañas y de las herramientas; patrón de los herreros, los mecánicos, los ingenieros, los soldados, los físicos y los químicos.

9. D eidad de la tierra, la agricultura y las cosechas; patrón de los labradores.

10. Los jimaguas cel estiales que gozan del amor paternal y maternal de todos los orishas, patrones de barberos y cirujanos.

11. Tribu de Nigeria.

12. M adre de la vida, considerada madre de todos los orishas. Representa al mar, fuente fundamental de la vida.

13. D ueña de la feminidad, la sexualidad y los ríos. Se le identifica como la patrona de Cuba, N uestra Señora de la Caridad del Cobre. 
estaban en Cuba como de los que arribaban, ya que renovaron elementos rituales quizás ya perdidos o en vías de extinción por la inclemencia y el trato inhumano de los terratenientes cubanos. Este intercambio produce un salto cualitativo y les permite dar un paso más firme hacia su futura identidad.

A mitad de este siglo surgen tres figuras casi simultáneamente en el tiempo: Andrés Facundo C risto de los D olores Petit (más conocido por Andrés Kimbisa en la Regla Kimbisa ${ }^{14}$ que él fundara y en la Sociedad Secreta Abakuá ${ }^{15}$, con la plaza de Isué de Bakokó Efor ${ }^{16}$ ), Lorenzo (o Ciriaco) Samá y la negra Adyai Latuán, de nación yoruba, quienes dejaron sus sellos impere cederos en las manifestaciones religiosas afrocubanas. Son estos dos últimos los que interesan a la hora de examinar la Regla de 0 cha.

\section{Precursores de la Regla de 0 cha o santería}

Andrés Petit, hombre culto, inteligente, terciario de la orden franciscana del convento de G uanabacoa era, además, indiobón («jefe principal») de Isue de Bakokó en la Sociedad Secreta Abakuá y Padre N kisil ${ }^{17}$ unifica todas las manifestaciones en estos sistemas religiosos, tanto de origen africano como católico por él conocidas, tratando de lograr, con esto, el más alto grado de espiritualidad posible dentro de la indisoluble ética de blancos y negros. Sintetizó las Reglas de Palo en la Regla Kimbisa, y mezcló la mayombería ${ }^{18}$ (originaria del Congo y Angola), la santería y el espiritismo (que ya comenzaba a dejar raíces profundas en el mundo religioso del negro), así como los santos de la I glesia católica. Éstos, a su vez, se imbrican en las creencias africanas con un folklórico surreal ismo tropical, en sus leyendas o relatos, identificados con los de las vírgenes y los mártires, que tanto conmovían la sensibilidad del pueblo creyente de nuestra isla caribeña.

Por su parte, Lorenzo (o C iriaco) Samá, que vivió en M atanzas, había consagrado Ifá́19. Cuando se trasladó a Regla, en La H abana, conoció a dos renombrados santeros ${ }^{20}$ : Tata $\mathrm{G}$ aytán y 0 bal ufadei 21 , quienes le exigieron que fuera asentado otra vez. Samá, un hombre con imaginación inagotable y ágil de pen-

14. M ezcla de mayombe, brillumba, el espiritismo y el santoral de la I glesia católica.

15. Sociedad secreta mágico-religiosa, exclusivamente integrada por hombres. Introducida en Cuba por esclavos procedentes del $\mathrm{C}$ alabar, $\mathrm{N}$ igeria.

16. Isué, el dueño de la consagración; Efor, tribu elegida, dueña del poder. Una de las tres principales y originarias potencias de Efor. D ata de 1863 en La H abana.

17. Sacerdote de la Regla Kimbisa. N kisi («espíritu»).

18. Trato directo con el nfunbe («espíritu del muerto») que reside en un receptáculo llamado fundamento, nganga, prenda, que encierra todas las cargas mágicas que vibran en la naturaleza.

19. Complejo sistema adivinatorio regido por el orisha $\mathrm{O}$ rula, que da nacimiento a todo lo que rige el mundo, las leyes de la natural eza, el cuerpo humano con sus virtudes y defectos, el presente, pasado y futuro y el mundo extracorpóreo. Tiene 16 odduns («detras») principales y 256 combinaciones.

20. Se les llama a los religiosos que practican la Regla de 0 cha o santería.

21. Nombre que recibió este religioso en el siglo pasado. 
samiento, reflexionó sobre la dispersión y la falta de unidad existente en los cultos yorubas. Tomó el nombre de 0 badimelli («rey coronado dos veces»), y se hizo inseparable de una negra de nación, yoruba, Ilamada L atuán. D e ella se dice que fue embarcada a Cuba en la década del ochenta y que tenía asentado a Changó, orisha que vino de su África misteriosa y profunda para establecerse en la idiosincrasia de nuestra nación. De este modo, Samá y Latuán concibieron la idea de unificar en un solo cuerpo litúrgico a las culturas yorubas, al cual denominaron Regla de 0 cha.

\section{La República de Cuba de 1900 a 1959}

A principios de la presente centuria aún supervivían diversas instituciones que se derivaban, de manera abierta o con variantes, de los antiguos cabildos de nación. Estas instituciones, con frecuencia, asumían la forma de sociedades de recreo, de socorro mutuo, de clubes y otras, algunas veces bajo la advocación de un santo católico.

N o obstante, los cabildos se hallaban, como tales, en franco proceso de decadencia o de desaparición. Su carácter de sociedad de socorro mutuo o de beneficencia, basada en el origen étnico común, había cedido el paso a un tipo de relaciones fundamentadas no en la nación u origen étnico, sino en un parentesco religioso determinado en los ritos de iniciación de la Regla de O cha. Así, poco a poco, en un proceso ciertamente involutivo, ciertos cabildos habaneros pasaron a ser tan sólo comparsas en los tradicionales festejos del carnaval, mientras que otros evolucionaron hacia la formación de casas templos, y se establecieron, en muchos casos, en los domicilios particulares de los propios santeros dedicados al culto de las divinidades u orishas de origen yoruba. A partir de entonces, lo habitual fue el surgimiento de las casas templos.

En las primeras décadas del siglo xx cubano tiene lugar una persecución de corte racista contra la población cubana de origen negro y mulato. Así, por ejemplo, en sus notas, don Fernando O rtiz recoge, en un manifiesto del año 1910 puesto en manos del presidente de la República, el sentir de la «Sociedad Santa Bárbara» - fundada en 1820 - la cual pedía que no se le persiguiera y que sus bienes no fuesen incautados por las autoridades comisionadas al efecto.

Producto de la sublevación del entonces ilegal Partido de los Independientes de Color, ocurrida en 1912 en la región oriental de Cuba y que reivindicaba mejoras para los negros y los mulatos, se desata una cruel represión contra negros y mestizos y se produce una vuelta al mundo subterráneo de las deidades del panteón afrocubano, las cuales, de nuevo, se encubrieron bajo las formas de los santos católicos.

Podemos explicar que en los mandatos presidenciales de la naciente República cubana, la discriminación racial toma matices diferentes desde su primer presidente, don Tomás Estrada Palma (1906); la intervención americana implanta y hace más evidente el racismo en el período 1906-1909, intentando quitar el voto a los negros e imponiéndole a su ejército la prohibición de mezclarse con pardos o mestizos. A continuación es nombrado presidente José M iguel 
Gómez (1909-1913), el cual pertenecía a una prestigiosa casa de paleros. Prosigue la discriminación racial y por ende la represión hacia las manifestaciones religiosas de origen africano en los períodos de los presidentes $\mathrm{G}$ arcía M enocal (1913-1921), Alfredo Zayas (1921-1925), G erardo M achado y Fulgencio Batista en su primer mandato (1940-1944). Este último, ferviente religioso dela Regla de 0 cha y las Reglas de Palo, tenía asentado al orisha Shangó.

$D$ urante estos períodos se observa una proyección gubernamental, a través de sus cuerpos represivos, de incul par a los negros descendientes de esclavos, a los criollos y a los mestizos de prácticas de brujería, fetichismo y, en múltiples casos, de asesinatos, robos y violaciones, a fin de sembrar el miedo en la población blanca del país. Todo esto aparece registrado en los anales de la policía de los distintos períodos presidenciales.

D e nuevo las manifestaciones religiosas de origen africano y ya afrocubanas pasan a la clandestinidad, y sus componentes, no ya sólo negros, sino también mestizos y blancos, la practican a puertas cerradas para no ser tildados de oscurantistas y brujeros.

N o es hasta 1940 que se promulga una nueva constitución de la República, la cual crea un clima favorable a la práctica de las religiones afrocubanas en el marco de las libertades civiles. No obstante, se dice que incluso en el período anterior a 1940, algunos presidentes de la recién instaurada R epública fueron iniciados en los cultos de la santería y ejercían su influencia sobre la población creyente humilde con fines electorales. Paralelamente, la Regla de 0 cha, en ese momento patrimonio de negros africanos, de mulatos y de sus descendientes, vio nacer un interés por ella en los sectores blancos de la población, sobre todo en las capas más humildes, las cuales comenzaron a incorporarse a sus cultos de una forma desprejuiciada.

En esta época alcanza especial relieve el hecho religioso conocido como «paral elismo», el cual considera que distintos sistemas religiosos son compatibles. Así, el creyente puede «acercarse más a la divinidad» practicando simultáneamente el catolicismo, el espiritismo, la R egla de 0 cha, la Regla de Palo y los preceptos religiosos de la Sociedad Secreta Abakuá.

Este entrecruzamiento de elementos ha dado lugar a diversas expresiones de religiosidad popular o de cultos llamados sincréticos. De este modo, el practicante cree poseer diversas «vías» para obtener en su favor la intercesión de la divinidad.

El clima político propiciado por la Constitución de 1940 favoreció el afloramiento de los cultos de origen yoruba y permitió, en cierta medida, los contactos entre los asiduos a las distintas casas templos, más o menos de forma incidental.

Esta situación se mantuvo hasta la década de los años cincuenta, época en que también comienzan a manifestarse criterios divergentes en cuanto a la aceptación de la membresía en la R egla de 0 cha. Esto, en cierta medida, debilitó los lazos que la vinculaban a los sacerdotes de I fá.

Las Reglas de Palo, conocidas por mayombe y traídas por esclavos procedentes del Congo y Angola, eran y son practicadas en grupos pequeños que 
nacen de un fundamento, el cual contiene la cosmogonía de cuanto vibra en la naturaleza. Sus miembros, por ser selectivos sus progenitores, tenían y tienen pocos adeptos; sin embargo, en el período de la República, gana popularidad por su misticismo y por sus curaciones a base de hierbas y palos. Sus sacerdotes, Ilamados paleros, son grandes conocedores de las propiedades medicinales de la natural eza. Aunque en años anteriores eran objeto de burlas y de persecuciones, comienzan, a partir de 1940, a ganar prestigio y a borrar 0, mejor dicho, a limpiar las consecuencias de la mala propaganda realizada por racistas sin escrúpulos. Ésta es una de las manifestaciones religiosas que más ha influenciado en la música cubana.

También en este período aflora en los puertos de $\mathrm{La} H$ abana, $\mathrm{M}$ atanzas y Cárdenas, sindicatos de uniones indisolubles: la Sociedad Secreta Abakuá, compuesta por esclavos del C alabar al sureste de $\mathrm{N}$ igeria, que ya se venían nucleando en los cabildos extramuros hacia el siglo XVII.

Este fenómeno de una sociedad constituida por hombres probados en todas las circunstancia de la vida, le permite la entrada al hombre blanco a mitad del siglo xIX, buscando con ello la preservación de este complejo ritual que es un fenómeno netamente cubano, ya que no se conserva en ningún otro país de Latinoamérica.

Esta sociedad perseguida, y vetada hasta nuestros tiempos, tiene una ética tan estricta como los principios o estatutos del Partido Comunista de nuestra revolución.

O tros rasgos característicos del período 1902-1958 son el establecimiento, a través de las grandes casas de babalawo ${ }^{22}$, del control de las tiradas para el vaticinio de los oddunes que regirán el año. Entre las casas de babalawos más antiguas se instituye la asociación de los $\mathrm{H}$ ijos de San Francisco, que agrupaba a importantes babalawos con vistas a mantener en activo la liturgia y el desarrollo religioso en una armonía.

En el período 1952-1958, bajo la dictadura de Fulgencio Batista, la religiosidad popular aflora como alivio ante tensiones políticas y sociales. Se dice también, como elemento a considerar, que el propio Batista y algunos de sus seguidores practicaban estos cultos.

Como dato curioso que ofrecemos al lector, podemos decir que el presidente Batista, religioso al fin, seguía las recomendaciones de las letras o vaticinios del año sobre la situación económica, política, ambiental y social del país, según lo marcara el sistema adivinatorio de Ifá.

En 1957, la letra oddún que sale (en el sistema adivinatorio de Ifá) viene hablando directamente con el jefe de Estado, Fulgencio Batista. Estas letras oddún se interpretan por medio de historias llamadas pattakies. Contaban que Changó iba a ser victima de una encerrona en su castillo, pero al ser avisado construyó una puerta secreta por la que logró escapar. $\mathrm{N}$ i corto ni perezoso Batista mandó construir una puerta secreta que daba a las escaleras de servi-

22. Sacerdotes de Ifá que adivinan según este método. 
cio, las cuales conducían a la azotea del palacio presidencial, y otra, en su residencia particular. El 13 de marzo de ese mismo año los miembros de la organización del Directorio Revolucionario atacaron la mansión presidencial, donde murieron estudiantes y policías. Pero Batista escapó por la puerta secreta. LoS estudiantes, que tenían el mapa interior del palacio, no sabían de esta construcción.

A partir del triunfo de la Revolución comienzan a producirse en La H abana movimientos internos y externos de población. D eterminados religiosos establecen sus casas de santo en Estados U nidos y toman la cultura religiosa de los emigrados residentes allá.

\section{C ontrapartida Revolución C ubana-religiones afrocubanas}

A partir de declararse la proyección socialista de la Revolución Cubana, comienza una nueva etapa para las religiones afrocubanas. Éstas, que han influenciado dejando su impronta en la pintura, la música, la literatura, el teatro, etc., ya forman parte de la joven identidad nacional. Ellas sufren el cambio político del éxodo de la espiritualidad del pueblo cubano, hacia un materialismo ajeno a su idiosincrasia. Sin ser «perseguidos», en las planillas y las biografías exigidas a la población para aspirar a algún centro laboral (todos estatales) aparecía un acápite donde se preguntaba: «¿A que religión pertenecía?». Si se contestaba afirmativamente, se sabía de antemano que no ocuparía ningún puesto directivo ni de importancia y, por supuesto, sería vetado para su militancia dentro de las filas del Partido Comunista. Con esto se cré una doble moral «[... ] digo que no, pero en silencio y a escondidas la practico», 0, como muchos hicieron, renegaron de sus raíces, botando sus santos, lo que equivale a decir, sus creencias. Esto crea un estado de incertidumbre por una imposición histórica ajena a nuestra cultura, en el que tres generaciones de cubanos se ven desarraigados de su espiritualidad.

A partir de 1990 comienza una apertura religiosa y el pueblo cubano retoma, con la fuerza de su sangre ancestral, estas manifestaciones que tanta influencia han ejecido sobre generaciones anteriores, haciendo de ellas una proyección al futuro incierto de la situación socioeconómica de su isla del Caribe, su Cuba de soles entrechocantes y de palmeras erectas a su destino.

La Regla de 0 cha o santería, practicada actualmente por un $80 \%$ de la población, conjuntamente con las Reglas de Palo y la Sociedad Secreta Abakuá, alzan sus ramas abrazando a sus hijos: los fieles y los renegados.

En C uba, los movimientos de población internos, desde las provincias hacia $\mathrm{La} \mathrm{H}$ abana, y principalmente desde $\mathrm{O}$ riente, aportan a la Regla de $\mathrm{O}$ cha el llamado espiritismo cruzado, forma religiosa de origen fon ${ }^{23}$, traída por los inmigrantes haitianos que venían, en épocas anteriores, para trabajar en las zafras azucareras y que se establecieron en las zonas orientales del país. En este

23. Etnia que se encuentra en el antiguo D ahomey meridional, actual República Popular de Benin. 
período, que registra una tercera fase evolutiva de esta Regla, se introduce también la adivinación mediante los vasos de agua y el uso de las barajas en los sistemas religiosos, así como inyecciones de diferentes manifestaciones en los practicantes de la Regla de $\mathrm{O}$ cha. $Y$ así sucesivamente, en lo que muy acertadamente llamara don Fernando O rtiz, El Ajiaco Criollo.
Alta corona de azúcar le tejen agudas cañas; no por coronada libre, sí de su corona esclava: reina del manto hacia afuera, del manto adentro, vasalla, triste como la más triste navega C uba en su mapa: un lagarto verde, con ojos de piedra y agua.

N icolás Guillén. Un largo lagarto verde.

Tabla 1. Relación de las vírgenes. Cuadro comparativo.

\begin{tabular}{|c|c|c|c|}
\hline Iglesia católica & $\begin{array}{l}\text { Regla de } 0 \text { cha, } \\
\text { santería }\end{array}$ & Regla de Palo & $\begin{array}{l}\text { Sociedad Secreta } \\
\text { Abakuá }\end{array}$ \\
\hline $\begin{array}{c}\text { Virgen de las } \\
\text { M ercedes }\end{array}$ & O bbatalá & M amá Kengue & Obandio \\
\hline Virgen de Regla & Yemayá & Baluande & O kande \\
\hline $\begin{array}{l}\text { Virgen de la } \\
\quad \text { Caridad del Cobre }\end{array}$ & Ochún & Chola Wengue & Yarina Bonde \\
\hline $\begin{array}{l}\text { Virgen de } \\
\quad \text { la C andelaria }\end{array}$ & O yá & M ariwanga & Onife \\
\hline
\end{tabular}

